\title{
Editorial
}

Psychotherapy and Psychosomatics

Psychother Psychosom 2006;75:69-71

DOI: $10.1159 / 000090890$

\section{The Biological Balance between Psychological Well-Being and Distress: A Clinician's Point of View}

\author{
Renato Pasquali \\ Division of Endocrinology, Department of Internal Medicine, S. Orsola-Malpighi Hospital, University of Bologna, \\ Bologna, Italy
}

As a clinician, I am very happy to see that we are now facing the synthesis of medical and psychological disciplines. Encouraged by the development of molecular biology, by sophisticated modern biotechnologies and, in general, by modern neuroscience, we have in the last few years started the still difficult task of understanding the biological correlates of psychological functions [1]. This fascinating adventure is only at the beginning, but we are getting a deeper knowledge of psychobiological correlates [2-4], impact of social life style, individual perception of adverse effects, and major chronic debilitating diseases, such as obesity, type 2 diabetes mellitus and cardiovascular diseases [5]. The article by Ryff et al. [6] published in this issue focuses on an interesting question in psychology: 'Is well-being merely the flip-side of studying psychological maladjustment' to adverse internal or external factors, 'or do well-being and ill-being constitute separate, independent dimensions of mental functioning?' As the authors state, biology provides good opportunities for assessing whether these psychological attitudes 'are opposite sides of the same coin, or represent distinct aspects of the same psychological functioning'. This may have some importance in understanding biological correlates of human mental disorders, leading, for example, to recurrent depression, and may therefore provide new tools for the treatment of this disorder. In addition, a deeper knowledge of the mechanisms of self-enhancing cogni- tion, such as well-being or ill-being perception, may be important in defining healthy or unhealthy biological profiles [7].

Per Bjorntorp, who unfortunately died 2 years ago, was one of the most prominent pioneers of this integrated way of understanding how psychological factors may affect susceptibility to develop chronic diseases. Being an excellent scientist and physician, he also proved to be a truly psychosomatic investigator, and his way of thinking has represented one of the routes in the expansion of modern applied psychobiology. Starting from the intuitive interpretation of animal studies and epidemiological evidence, he and his group developed the concept that maladaptation to a long list of environmental stressors may have a considerable impact on the development of central obesity and the metabolic syndrome, including hypertension and type 2 diabetes, therefore increasing individual susceptibility to cardiovascular events $[8,9]$. They provided unequivocal data supporting the fact that subjects of both sexes with traits of depression and anxiety often had centralized body fat. These characteristics were, among others, depressed mood, frequent use of antidepressants and anxiolytic drugs as well as various sleeping difficulties. Additional studies by his group and others [10] have shown that the associations were also evident with a long list of adverse environmental conditions, including low socioeconomical status, school education and low in-

\section{KARGER}

Fax +4161306 1234

E-Mail karger@karger.ch

www.karger.com
(C) 2006 S. Karger AG, Basel

0033-3190/06/0752-0069\$23.50/0

Accessible online at:

www.karger.com/pps
Prof. Renato Pasquali

Division of Endocrinology

S. Orsola-Malpighi Hospital, University of Bologna

IT-40138 Bologna (Italy)

Tel. +39051636 4147, Fax +390516363080, E-Mail renato.pasquali@unibo.it 
Fig. 1. Principal perturbations involved in a detrimental adaptation to environmental stressors. Modified from Bjorntop [9], with permission.

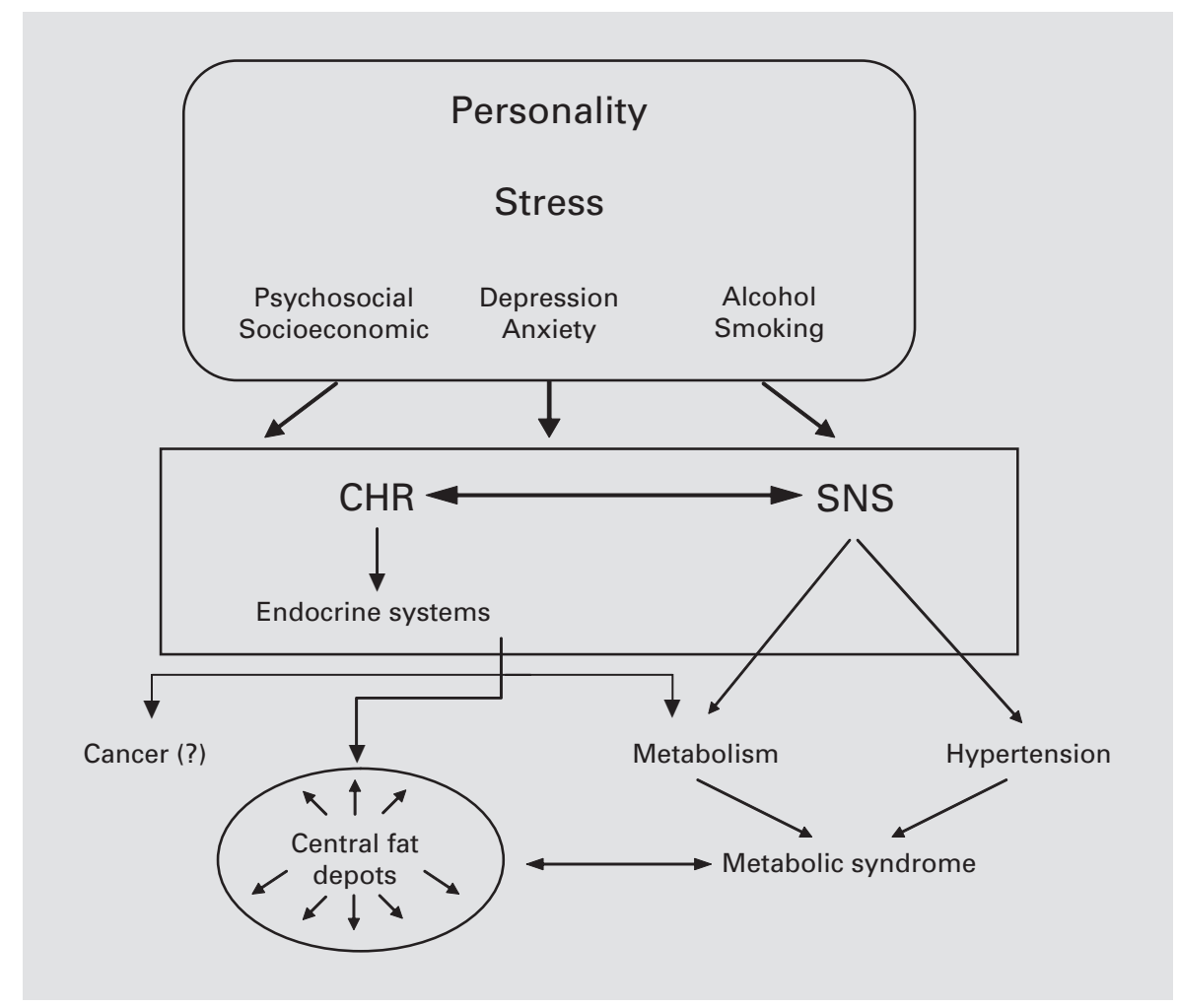

come, and many other social, psychosocial and cultural handicaps. Finally, they demonstrated that body fat tends to be stored in central depots in certain types of personality, which includes both normal variants and what has been defined a personality disorder (schizoid and avoidant, dependent and passive, and aggressive characteristics) [9]. One of the major merits of Bjorntorp's scientific work was the definition of the principal neuroendocrine perturbations involved in such a detrimental adaptation (maladaptation) to environmental stressors, with particular emphasis on the hypothalamic pituitary-adrenal axis and the sympathetic nervous system [2] (fig. 1). These endocrine systems are important for adequate adaptation to both acute and chronic stress [3]. Longitudinal studies in experimental animals [11] and cross-sectional epidemiological, as well as clinical, studies performed in humans [12, 13], have clearly demonstrated that long-term exposure to chronic environmental stressors may lead to abdominal obesity and metabolic disturbances defining the metabolic syndrome, increased hypothalamic pituitary-adrenal axis activity and hyperactivation of the catecholaminergic system. In their study, Ryff et al. [6] assessed multiple aspects of psychological well-being (eudaimonic, hedonic) and ill-being (depression, anxiety, anger) in a sample of aging women in whom several endocrine (salivary free cortisol, norepinephrine, epinephrine, DHEA-S) and cardiovascular factors (weight, height, waist-to-hip ratio, systolic and diastolic blood pressure, HDL-cholesterol, total/HDL-cholesterol ratio and glycosylated hemoglobin) were also measured. They found that measures of psychological well-being and ill-being were significantly linked with numerous hormonal and cardiovascular biomarkers, particularly in older subjects. Intriguingly, they found significant associations between different measures of well-being and ill-being and salivary free cortisol, blood levels of norepinephrine, DHEA-S, and HDL cholesterol, waist-to-hip ratio (an anthropometric index of body fat distribution) and systolic blood pressure. They supported a distinction between psychological well-being and ill-being on the basis of several endocrine and cardiovascular parameters. These findings clearly support the structural link between psychological functions and biological markers, which form a unique entity, with different aspects and functions, but with a unique otherwise complex network which guarantees biological integrity. Although this study has some limitations due to the number of biological markers measured and the small number of subjects investigated, it nonethe- 
less provides an important contribution in the difficult task we have in the understanding of neuropsychological functions and hormonal and nonhormonal regulatory factors. In addition, they indirectly support the original view of Per Bjorntorp reported above. Continuous ex- panding of our knowledge in the area of mental disorders as well as chronic degenerative metabolic and cardiovascular diseases will certainly suggest potential new directions in the treatment of these disorders, including psychological counseling and management.

\section{References}

1 McEwen BS: The neurobiology and neuroendocrinology of stress. Implications for posttraumatic stress disorder from a basic science perspective. Psychiatr Clin North Am 2002; 25:469-494.

2 Chrousos GP: Stressors, stress, and neuroendocrine integration of the adaptive response. The 1997 Hans Seyle Memorial Lecture. Ann NY Acad Sci 1998;851:311-335.

3 McEwen BS: Protective and damaging effects of stress mediators. N Engl J Med 1998;338: 171-179.

4 Dallman MF: Chronic stress and obesity: a new view of 'comfort foods'. Prod Natl Acad Sci 2003;1000:11696-11701.

5 Hjemdahl P: Stress and the metabolic syndrome. An interesting but enigmatic association. Circulation 2002;106:2634-2636.
6 Ryff CD, Dienberg Love G, Urry HL, Muller D, Rosenkranz MA, Friedmann EM, Davidson RJ, Singer B: Psychological well-being and ill-being: do they have distinct or mirrored biological correlates? Psychother Psychosom 2006; 75:85-95.

7 Taylor SE, Lerner JS, Sherman DK, Sage RM, McDowell NK: Are self-enhancing cognitions associated with healthy or unhealthy biological profiles? J Pers Soc Psych 2003;85:605-615.

8 Bjorntorp P: Do stress reactions cause abdominal obesity and comorbidities? Obes Rev 2001;2:73-86.

9 Bjorntorp P: Centralization of body fat; in Bjorntorp P (ed): International Textbook of Obesity. New York, Wiley, 2001, pp 213224.
10 Cota D, Vicennati V, Ceroni L, Morselli-Labate AM, Pasquali R: Relationship between socio-economic and cultural status, psychological factors and body fat distribution in middle-aged women living in Northern Italy. Eat Weight Disord 2001;6:205-213.

11 Kaplan JR, Adams MR, Clarkson TB, Manuck SB, Shively CA, Williams JK: Psychosocial factors, sex differences, and atherosclerosis: lessons from animal models. Psychosom Med 1996;58:598-611.

12 Rosmond R, Dallman MF, Bjorntorp P: Stressrelated cortisol secretion in men: relationships with abdominal obesity and endocrine, metabolic and hemodynamic abnormalities. J Clin Endocrinol Metab 1998;83:1853-1859.

13 Pasquali R, Vicennati V: Activity of the hypothalamic-pituitary-adrenal axis in different obesity phenotypes. Int $\mathrm{J}$ Obes Relat Metab Disord 2000;24(suppl 2):S47-S91. 